\title{
A Survival Analysis of Gastric or Colorectal Cancer Patients Treated With Surgery: Comparison of Capital and a Non-capital City
}

\author{
Nam-Soo Hong ${ }^{1,2}$, Kyeong Soo Lee ${ }^{3}$, Sin Kam ${ }^{1}$, Gyu Seog Choi ${ }^{4}$, Oh Kyoung Kwon ${ }^{5}$, Dong Hee Ryu' ${ }^{2}$, Sang Won Kim ${ }^{3}$ \\ ${ }^{1}$ Department of Preventive Medicine, Kyungpook National University School of Medicine, Daegu; ${ }^{2}$ Daegu-Kyungpook Regional Cancer Center, \\ Kyungpook National University Medical Center, Daegu; ${ }^{3}$ Department of Preventive Medicine and Public Health, Yeungnam University College of \\ Medicine, Daegu; ${ }^{4}$ Colorectal Cancer Center, Kyungpook National University Medical Center, Daegu; ${ }^{5}$ Gastric Cancer Center, Kyungpook National \\ University Medical Center, Daegu, Korea
}

Objectives: The objective of the present study was to compare prognosis of patients with gastric or colorectal cancer according to places where they received surgeries.

Methods: The cancer patients underwent surgeries in sampled hospitals located in Daegu were matched 1:1 to the patients who visited sampled hospitals in Seoul using propensity score method. After the occurrences of death were examined, Kaplan-Meier method was used for survival analysis and the log-rank test was performed to compare the survival curves.

Results: A total of six out of 291 gastric cancer patients who had surgeries in Daegu died (2.1\%) and ten deaths (3.4\%) occurred from patients went Seoul hospitals. Out of 84 gastric cancer patients who had chemotherapy after surgeries in Daegu, 13 (15.5\%) patients died while 18 (21.4\%) deaths occurred among patients underwent surgeries in Seoul. Six deaths (6.9\%) out of 87 colorectal cancer patients who had surgeries in Daegu were reported. Five patients (5.7\%) died among the patients underwent surgeries in Seoul. Among the colorectal cancer patients with chemotherapy after surgeries, 13 patients (12.4\%) who visited hospitals in Daegu and 14 (13.3\%) patients who used medical centers in Seoul died. There were no significant differences according to places where patients used medical services.

Conclusions: The result of this study is expected to be used as basic data for policy making to resolve centralization problem of cancer patients and to help patients to make rational choices in selection of medical centers.

Key words: Stomach neoplasms, Colorectal neoplasms, Survival analysis, Health services

Received: March 17, 2017 Accepted: June 21, 2017

Corresponding author: Kyeong Soo Lee, MD, PhD

170 Hyeonchung-ro, Nam-gu, Daegu 42415, Korea

Tel: +82-53-640-6953, Fax: +82-53-653-2061

E-mail: drkslee@ynu.ac.kr

This is an Open Access article distributed under the terms of the Creative Commons Attribution Non-Commercial License (http://creativecommons.org/licenses/bync/4.0/) which permits unrestricted non-commercial use, distribution, and reproduction in any medium, provided the original work is properly cited.

\section{INTRODUCTION}

Utilization of medical services by patients from non-capital regions in Seoul, the capital city of Korea, have been increasing. Big-sized hospitals in Seoul, which have been expanding in size in the 2000s with large scale investments, accelerated this concentration phenomenon. In addition, due to the establishment of Korea Train Express, geographical constraints 
on medical service utilizations decreased and inter-provincial movements are intensified [1]. The centralization stands out amongst cancer patients compared to patients suffering from other diseases. According to a previous study examined medical utilizations in Seoul by patients from non-capital regions, approximately $15.6 \%$ of patients from non-capital regions visited medical institutions in Seoul while $32.3 \%$ of cancer patients from non-capital regions visited hospitals in Seoul [2]. Other studies investigated utilization of medical services by cancer patients also exhibited similar results [3-6].

The increase in the use of medical services in Seoul by cancer patients is not only a matter of expanding medical areas, but also an indicative of problems such as personal economic burden, increased social costs, and collapse of health care delivery system. Of course, in the presence of imbalanced distribution of regional medical resources, it is patients' rights to be provided with better medical services if they want. It should be pointed out that unnecessary inter-provincial movements would hinder the continuity of medical care and endanger patients if in emergency situations; therefore the best medical service cannot be provided to the patients. Medical expenses, social costs, and national medical expenses would also be affected by this concentration phenomenon [5]. Indiscriminate use of medical services in big-sized hospitals in Seoul drew even relatively mild patients and restricted medical utilizations of patients with severe and rare diseases [2].

One of the most important reasons why many cancer patients from non-capital regions prefer visiting big-sized hospitals in Seoul can be inferred from previous study results about determining factors of selection of medical institutions. Qualitative aspects of medical services such as conditions of facility, instruments or equipment, and reputation of healthcare personnel were important in selection of medical institutions especially for severe diseases or diseases that require high-technique [2]. When surgical treatment is required, a physician's reputation was the most important factor to consider in selection of hospital, followed by hospital's reputation [7]. Factors affecting inpatient medical utilizations were number of beds and possession of high cost medical equipment. Compared to hospitals, the use of medical services were higher in general hospitals (odds ratio $[\mathrm{OR}], 2.0$ ) and specialized general hospitals (OR, 4.7). The rate of admission was approximately 3.3 times higher when medical institutions possessed computed tomography [8]. It can be summarized that determining factors of hospital selection among cancer patients include tech- niques and skills of physicians, hospitals' reputation, and possession of excellent and approved medical facilities [9]. However, the effect of these factors on patients' conditions are not objectively proved but are often believed based on obscure expectations of patients or subjective experiences of patients' acquaintances. Not enough studies were conducted to verify this generally accepted perception of patients that medical services in big-sized metropolitan hospitals are better than those in non-capital regions.

The objective of the present study was to compare prognosis of patients with gastric or colorectal cancer, the most prevalent types of cancer except for thyroid cancer, according to places where patients received surgeries. The result of this study is expected to be basic data for policy making to resolve centralization of cancer patients to Seoul and to help patients to make rational choices in selection of medical institutions.

\section{METHODS}

\section{Study Population}

The present study is a secondary data analysis study using medical utilization data from National Health Insurance Corporation. The use of data was approved by National Health Insurance Corporation (serial no. NHIS-2016-1-110) and the study was also approved by the institutional review board of Kyungpook National University Hospital.

Among patients whose registered residential addresses were within Daegu, patients aged older than 18 and first diagnosed with gastric or colorectal cancer from 2009 to 2012 were selected as the study subjects. A total of 11617 patients were diagnosed with either gastric or colorectal cancer in Daegu, 5975 or 5642 , respectively during the period.

Korean Standard Classification of Diseases which is based on International Statistical Classification of Diseases, 10th revision (ICD-10) was used for disease definition. If a patient's primary diagnosis or secondary diagnosis code was C16 (malignant neoplasm of stomach), he/she was defined as a gastric cancer patient in the study. When a primary or a secondary diagnosis code consisted $\mathrm{C} 18, \mathrm{C} 19$, or $\mathrm{C} 20$ (C18, malignant neoplasm of colon; C19, malignant neoplasm of rectosigmoid junction; C20, malignant neoplasm of rectum), he/she was defined as a colorectal cancer patient.

Patients who had surgeries at any one of five university hospitals (Kyungpook National University Hospital, Kyungpook National University Medical Center, Yeungnam University 
Medical Center, Keimyung University Dongsan Medical Center, and Daegu Catholic University Medical Center) in Daegu province or six big-sized hospitals in Seoul with more than 1300 inpatients beds (Seoul National University Hospital, Seoul National University Bundang Hospital, Samsung Medical Center, Asan Medical Center, Yonsei University Severance Hospital, Catholic University of Korea Seoul St. Mary's Hospital) under the defined diagnosis were included in the present study.

Exclusion criteria for sample subjects included any previous cancer history, no surgical treatment for their conditions, or chemotherapy history before surgical treatment. Patients with any types of cancer history including gastric or colorectal cancer before their first diagnosis were excluded since that would affect their prognosis. Patients who had no surgery after the diagnosis were excluded from the study and patients who received endoscopic resection of any types were treated as ones without surgeries. The treatment of choice for gastric or colorectal cancer is a radical resection [10-12]. Patients whose primary treatment was chemotherapeutical treatment were also excluded from the study because they are treated as advanced cancer patients since a primary care for advanced cancer is chemotherapy.

The final number of study subjects for gastric and colorectal cancer were 1909 and 1138, respectively by excluding patients with previous cancer histories (stomach cancer, 590; colorectal cancer, 575), who had no surgeries (stomach cancer, 2413; colorectal cancer, 2313), and whose primary treatment was not radical resection of cancer (stomach cancer, 245; colorectal cancer, 367).

A total of 1531 gastric cancer patients visited the selected hospitals in Daegu and 378 patients used the sample hospitals in Seoul. The number of colorectal cancer patients who used the selected hospitals located in Daegu was 936 and 202 patients used medical services at hospitals in Seoul. The cancer patients underwent surgeries in sampled hospitals located in Daegu were matched 1:1 to the patients who visited sampled medical institutions in Seoul using propensity score. A total of 750 gastric cancer patients and 384 colorectal cancer patients were included in the final analysis.

\section{Measurements}

The deaths of the study subjects starting from the first resection of malignant neoplasm until December 31, 2015, were examined. The statistics data for death from Statistics Korea were used for the evaluation of deaths. The date of surgery was defined as the earliest date of medical prescription records with selected electronic data interchange (EDI) surgery codes. The EDI codes for surgeries were selected based on consultation from gastric and colorectal cancer specialists and are presented in Supplemental Table 1. When the initiation date of chemotherapy was earlier than the date of the first surgery, it was excluded from the study. Applications of chemotherapy on patients were confirmed with drug classification code number of 421 (anti-cancer agents) and the initiation date of chemotherapeutical treatment was defined as the date anti-cancer agents were prescribed.

Covariates included sex, age, household income, and comorbidities of the study subjects. Age was categorized as $<30,30-39,40-49,50-59,60-69,70-79$ and $\geq 80$. The health insurance premium and insurance eligibility represented household income in this study and was categorized into quintiles (lowest [Medicaid], lower, middle, higher, and highest). The presences of comorbidities are known to influence prognosis of cancer patients $[13,14]$ and for evaluation of comorbidities, Charlson comorbidity index, one of the most widely used indexes [15] was used. Since ICD-10 is used for health insurance claim data, the algorithm suggested by Quan et al. [15] was used in the study (Supplemental Table 2). The index was calculated only for those cases identified more than once in the claim data for 2 years from the date of the first insurance claim of gastric or colorectal cancer using the primary or secondary diagnosis [16].

\section{Statistical Analysis}

The logistic regression was performed to calculate the propensity score and sex, age, household income, and comorbidities were used as covariates in order to control the effect of general characteristics of study subjects that might have influence on the overall prognosis. The minimum distance method is used to match patients with similar propensity scores.

In addition, stratified analyses were performed in order to control the effect of cancer stages. Since the data provided by National Health Insurance Corporation do not contain specific information about stages of cancer, the study sample was further classified into 2 groups, surgery (group 1) or chemotherapy after surgery (group 2). Referred to clinical guidelines for gastric and colorectal cancer [10-12] and the specialists, the cancer stage of patients who underwent chemotherapy after surgery was considered as a high-grade.

In order to compare general characteristics of study subjects 
Table 1. General characteristics of gastric cancer patients ${ }^{1}$ in Daegu according to where they received surgery

\begin{tabular}{|c|c|c|c|c|c|c|c|}
\hline & & \multicolumn{3}{|c|}{ Unmatched } & \multicolumn{3}{|c|}{ 1:1 Matched } \\
\hline & & Seoul & Daegu & $p$-value ${ }^{2}$ & Seoul & Daegu & $p$-value ${ }^{2}$ \\
\hline \multicolumn{8}{|l|}{ Group 1 (surgery) } \\
\hline \multirow[t]{2}{*}{ Sex } & Male & $197(26.1)$ & $557(73.9)$ & 0.08 & $196(67.4)$ & $189(65.0)$ & 0.54 \\
\hline & Female & $97(21.7)$ & $350(78.3)$ & & $95(32.6)$ & $102(35.0)$ & \\
\hline \multirow{4}{*}{ Age (y) } & $40-49$ & $67(28.1)$ & $171(71.9)$ & & $65(22.3)$ & $69(23.7)$ & \\
\hline & $50-59$ & $101(26.2)$ & $284(73.8)$ & & $101(34.7)$ & $113(38.8)$ & \\
\hline & $60-69$ & $59(20.1)$ & $234(79.9)$ & & $59(20.3)$ & $62(21.3)$ & \\
\hline & 70-79 & $25(15.1)$ & $141(84.9)$ & & $25(8.6)$ & $18(6.2)$ & \\
\hline \multirow{2}{*}{ Household income } & Higher & $65(24.0)$ & $206(76.0)$ & & $65(22.3)$ & $69(23.7)$ & \\
\hline & Highest & $156(32.0)$ & $331(68.0)$ & & $153(52.6)$ & $158(54.3)$ & \\
\hline Charlson comorbidity index & & $0.96 \pm 1.20$ & $1.14 \pm 1.44$ & 0.03 & $0.96 \pm 0.82$ & $0.94 \pm 0.78$ & 0.85 \\
\hline \multicolumn{8}{|c|}{ Group 2 (chemotherapy after surgery) } \\
\hline Total (n) & & 84 & 624 & & 84 & 84 & \\
\hline \multirow[t]{2}{*}{ Sex } & Male & $55(11.5)$ & $421(88.5)$ & 0.71 & $55(65.5)$ & $50(59.5)$ & 0.43 \\
\hline & Female & $29(12.5)$ & $203(87.5)$ & & $29(34.5)$ & $34(40.5)$ & \\
\hline \multirow[t]{2}{*}{ Age (y) } & $<30$ & $3(30.0)$ & $7(70.0)$ & 0.009 & $3(3.6)$ & $3(3.6)$ & 0.45 \\
\hline & $30-39$ & $7(15.2)$ & 39 (84.8) & & $7(8.3)$ & $11(13.1)$ & \\
\hline \multirow{4}{*}{ Household income } & Lower & $17(10.4)$ & $147(89.6)$ & & $17(20.2)$ & $23(27.4)$ & \\
\hline & Middle & $5(4.4)$ & $109(95.6)$ & & $5(6.0)$ & $4(4.8)$ & \\
\hline & Higher & $22(12.1)$ & $159(87.9)$ & & $22(26.2)$ & $23(27.4)$ & \\
\hline & Highest & $40(17.9)$ & $184(82.1)$ & & $40(47.6)$ & $34(40.5)$ & \\
\hline Charlson comorbidity index & & $0.86 \pm 1.20$ & $0.82 \pm 1.12$ & 0.76 & $0.86 \pm 0.60$ & $0.83 \pm 0.60$ & 0.89 \\
\hline
\end{tabular}

Values are presented as number (\%) or mean \pm standard deviation.

${ }^{1}$ The patients who underwent surgery in Daegu were matched 1:1 to patients who visited sampled medical institutions in Seoul using propensity scores.

${ }^{2}$ The chi-square test and Student $t$-test were performed.

the chi-square tests and Student's t-tests were performed. Multivariate analyses using the Cox's proportional hazard model were performed to compare survival rates according to areas where patients underwent surgeries and to obtain hazard ratio (HR) controlling other factors that affect survival of the subjects. The Kaplan-Meier method was used for survival analysis according to place where patients used medical services and the log-rank test was performed to compare the sur- vival curves. All statistical analyses were performed with SAS version 9.4 (SAS Institute Inc., Cary, NC, USA) and a p-value $<0.05$ was considered to indicate statistical significance.

\section{RESULTS}

Table 1 represents general characteristics of gastric cancer patients and that of colorectal cancer patients are presented 
Table 2. General characteristics of colorectal cancer patients ${ }^{1}$ in Daegu according to where they received surgery

\begin{tabular}{|c|c|c|c|c|c|c|c|}
\hline & & \multicolumn{3}{|c|}{ Unmatched } & \multicolumn{3}{|c|}{ 1:1 Matched } \\
\hline & & Seoul & Daegu & $p$-value ${ }^{2}$ & Seoul & Daegu & $p$-value ${ }^{2}$ \\
\hline \multicolumn{8}{|l|}{ Group 1 (surgery) } \\
\hline \multirow[t]{2}{*}{ Sex } & Male & $57(18.0)$ & $260(82.0)$ & 0.13 & $56(64.4)$ & $65(74.7)$ & 0.14 \\
\hline & Female & 32 (13.2) & $210(86.8)$ & & $31(35.6)$ & $22(25.3)$ & \\
\hline \multirow{5}{*}{ Age (y) } & $40-49$ & $20(29.0)$ & $49(71.0)$ & & $18(20.7)$ & $12(13.8)$ & \\
\hline & $50-59$ & 30 (22.9) & $101(77.1)$ & & $30(34.5)$ & $25(28.7)$ & \\
\hline & $60-69$ & $24(14.3)$ & $144(85.7)$ & & $24(27.6)$ & $23(26.4)$ & \\
\hline & $70-79$ & $10(7.3)$ & $127(92.7)$ & & $10(11.5)$ & $17(19.5)$ & \\
\hline & $\geq 80$ & $3(7.7)$ & 36 (92.3) & & $3(3.5)$ & $5(5.8)$ & \\
\hline \multirow{2}{*}{ Household income } & Higher & $10(7.0)$ & $132(93.0)$ & & $10(11.5)$ & $8(9.2)$ & \\
\hline & Highest & $58(24.8)$ & $176(75.2)$ & & $56(64.4)$ & $63(72.4)$ & \\
\hline Charlson comorbidity index & & $1.19 \pm 1.30$ & $1.33 \pm 1.53$ & 0.43 & $1.21 \pm 0.93$ & $1.25 \pm 0.93$ & 0.83 \\
\hline \multicolumn{8}{|c|}{ Group 2 (chemotherapy after surgery) } \\
\hline Total (n) & & 113 & 466 & & 105 & 105 & \\
\hline \multirow[t]{2}{*}{ Sex } & Male & $71(19.0)$ & $302(81.0)$ & 0.69 & $68(64.8)$ & $71(67.6)$ & 0.66 \\
\hline & Female & $42(20.4)$ & $164(79.6)$ & & $37(35.2)$ & $34(32.4)$ & \\
\hline \multirow[t]{2}{*}{ Age (y) } & $<30$ & $2(66.7)$ & $1(33.3)$ & $<0.001$ & $1(1.0)$ & $1(1.0)$ & 0.86 \\
\hline & $30-39$ & $11(39.3)$ & $17(60.7)$ & & $9(8.6)$ & $7(6.7)$ & \\
\hline \multirow{4}{*}{ Household income } & Lower & $20(17.7)$ & $93(82.3)$ & & $19(18.1)$ & $17(16.2)$ & \\
\hline & Middle & $15(16.5)$ & 76 (83.5) & & $15(14.3)$ & 14 (13.3) & \\
\hline & Higher & $22(17.2)$ & $106(82.8)$ & & $21(20.0)$ & $27(25.7)$ & \\
\hline & Highest & $56(26.5)$ & $155(73.5)$ & & $50(47.6)$ & $47(44.8)$ & \\
\hline Charlson comorbidity index & & $0.56 \pm 0.80$ & $1.06 \pm 1.41$ & $<0.001$ & $0.59 \pm 0.43$ & $0.49 \pm 0.33$ & 0.35 \\
\hline
\end{tabular}

Values are presented as number (\%) or mean \pm standard deviation.

${ }^{1}$ The patients who underwent surgery in Daegu were matched 1:1 to the patients who visited sampled medical institutions in Seoul using propensity scores.

${ }^{2}$ The chi-square test and Student $t$-test were performed.

in Table 2. For both diseases, sex, age, household income, and comorbidity index were not significantly different according to locations where patients used medical services after matching. The results of stratified analysis within patients with the same disorder showed no significant difference between the groups either.

Table 3 represents the result of multivariate analyses using the Cox's proportional hazard model. The HRs of death due to gastric or colorectal cancer were not significantly different according to places where patients received the surgeries.

A total of six out of 291 gastric cancer patients who had surgeries in Daegu died (2.1\%) and ten deaths (3.4\%) occurred from patients used medical services in Seoul hospitals. The survival rates of gastric cancer patients, who only underwent surgical treatments, according to places of medical utilizations were not significantly different with a $p$-value of 0.35 (Figure 
Table 3. Adjusted hazard ratio $(\mathrm{aHR})^{1}$ according to where patients received surgery

\begin{tabular}{lcc}
\hline & Group 1 (surgery) & $\begin{array}{c}\text { Group 2 (chemotherapy } \\
\text { after surgery) }\end{array}$ \\
\hline $\begin{array}{l}\text { Gastric cancer } \\
\text { Seoul }\end{array}$ & 1.00 (reference) & 1.00 (reference) \\
Daegu & $0.85(0.42,1.72)$ & $0.83(0.50,1.38)$ \\
Colorectal cancer & & \\
Seoul & 1.00 (reference) & 1.00 (reference) \\
Daegu & $1.56(0.61,3.93)$ & $1.37(0.78,2.40)$ \\
\hline
\end{tabular}

Values are presented as aHR (95\% confidence interval).

${ }^{1}$ aHR was adjusted for sex, age, household income, and comorbidity index.
1A). Out of 84 gastric cancer patients who had chemotherapy after surgeries in Daegu, 13 (15.5\%) patients died while 18 (21.4\%) deaths occurred among patients visited big-sized hospitals in Seoul. The probability of survival were not significantly different with a $p$-value of 0.21 (Figure 1B).

Six deaths (6.9\%) out of 87 colorectal cancer patients who had surgeries in Daegu were reported. Five patients (5.7\%) died among the patients who used medical services in Seoul. There was no significant difference $(p=0.70)$ (Figure 2A). Among the colorectal cancer patients who had chemotherapeutical treatments after surgeries, a total of 13 patients (12.4\%) who visited hospitals in Daegu and 14 (13.3\%) pa-

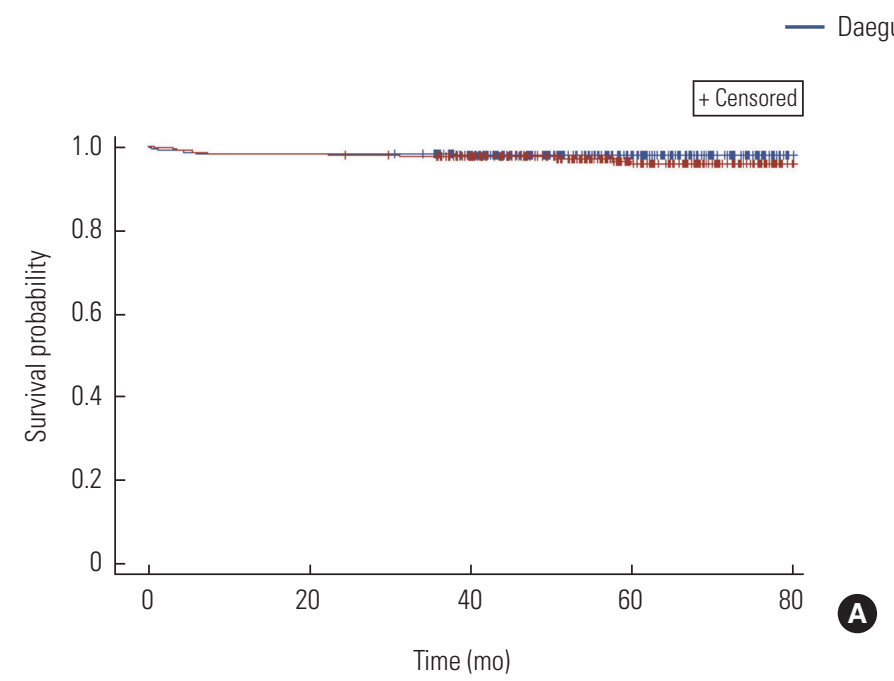

Figure 1. Survival analysis of gastric cancer patients. (A) Group 1 (surgery) ( $p=0.35)$. (B) Group 2 (chemotherapy after surgery) $(p=0.21)$.

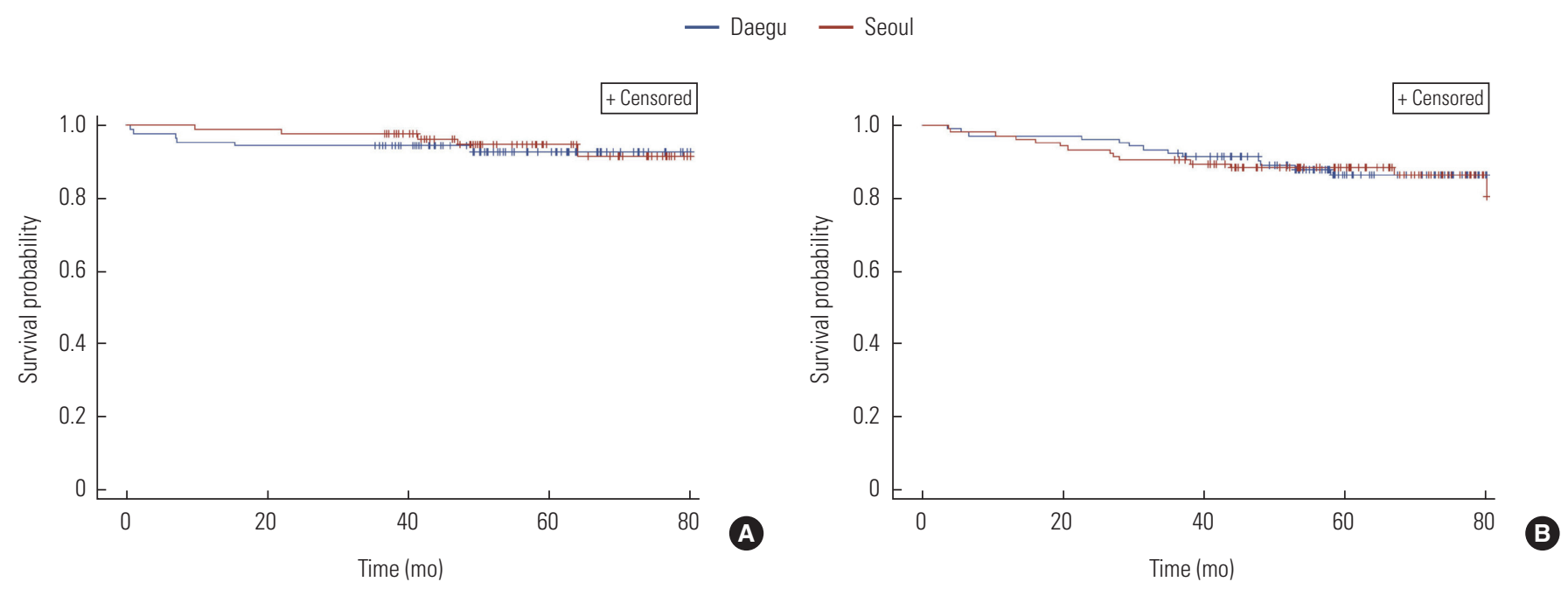

Figure 2. Survival analysis of colorectal cancer patients. (A) Group 1 (surgery) ( $p=0.70)$. (B) Group 2 (chemotherapy after surgery) $(p=0.80)$. 
tients who used medical centers in Seoul died. There was no statistical significance with a $p$-value of 0.80 (Figure 2B).

\section{DISCUSSION}

The present study showed that the survival probabilities of gastric or colorectal cancer patients in Daegu were not significantly different according to places where they used medical services. The outcome of complicated medical procedures such as cancer surgeries are known to be affected by the surgical volume of that hospital. Hospitals with a large surgical volume showed better outcome than hospitals with a small volume of surgery [17-21]. It is possible to conclude that one of the reasons why no significant difference was detected in the present study was because sampled hospitals in Daegu also have sufficient experiences with cancer patients as the selected hospitals in Seoul. The number of newly developed gastric cancer patients in Daegu was 1373 and that of colorectal cancer patients in Daegu was 1336. In addition, 2080 gastric cancer patients and 1818 colorectal cancer patients developed in the neighboring area, Gyeongbuk province [22], so that it can be assumed that the selected hospitals in Daegu had sufficient experience in surgical treatment of gastric and colorectal cancer with sufficient patients. Gastric and colorectal cancer are the most prevalent cancer except for thyroid cancer in Korea and for these types of cancer sufficient medical experience and cooperation system with expertise are also placed in non-capital regions as well.

Previous studies reported that prognosis of patients with rare types of cancer was enhanced after referred to hospitals with large volumes [23,24]. Physicians at non-capital regions do not have sufficient experiences with rare cancer patients so it can be assumed that the outcome of patients who used medical services at big-sized hospitals in Seoul could be better in this case. However, this does not support indiscriminate referral of patients to Seoul. In addition to taking the risk of traveling physically and painfully whenever needed, patients might have to waste their precious time for new medical staff to evaluate their previous conditions if they went to medical centers in their residential areas in an emergency. It would be desirable to focus on the regional university hospitals to guarantee improved and specialized medical services for selected types of cancer and to secure the amount of medical care with a high quality services. An adequate referral system established among non-capital hospitals is also necessary.
The present study results do not support the idea that utilization of medical services in non-capital regions is equivalent to medical services in Seoul. Of course, the phenomenon can partially be explained by the consumers' preference. There is no regulation or restrictions of choosing hospitals based on patients' preference in Korea since patients' freedom and rights are valued the most and the health insurance system made it possible for every single one of its citizens to be provided with medical services with the least barriers. Patients have a tendency of evaluating medical centers based on external factors such as hospital volume, convenient facilities, equipment, and reputation heard from acquaintances [25]. Although, the movements of patients can be explained by their preference, patients do not only measure the outcome of the services but also every aspect they experience whenever they use medical services. In this respect, comprehensive medical services are required for cancer patients. It takes a tremendous amount of effort and time for cancer patients to resume one's life after appropriate medical treatment, surgical resection of malignant neoplasm, is finished. Not only physical and social constraints but also emotional anxiety and fear of metastasis and possible recurrence are obstacles to overcome. The reported prevalence rate of major depression disorder in cancer patients is ranged from 10 to $25 \%$, which is approximately four times higher than that of general population [26]. A research has shown that cancer patients are not adequately provided with essential medical services of other diseases than cancer [27]. In addition to medical treatment of cancer, supportive medical care and social networks are also required for cancer patients. Hospitals located in non-capital regions should be prepared with comprehensive medical care for cancer patients with this regard. However, in order for patients to make appropriate choices in medical utilization, relevant information about service quality and knowledge to compare each medical institution are required. Since lack of professional knowledge in medicine and related fields prevent them from making right decisions, means that can help them to evaluate medical centers which suit their demands and preference are necessary. Only limited information about quantitative and qualitative aspects of medical services are available and even these are not easily accessible and comparable.

Reasonable medical utilization should increase the quality and value of medical services, and the value includes the concept of cost effectiveness. The American Board of Internal Medicine suggested that reasonable medical use should avoid 
overuse, misuse, and underuse of medical services [28]. LipitzSnyderman and Bach [29] classified overuse into three categories; benefit-harm tradeoff (potential harms exceed the potential benefits), benefit-cost tradeoff (potential benefits is small relative to the costs), consideration of patient preference (tradeoffs between outcomes such as survival and quality of life). The present study results showed that the potential benefits of utilizing big-sized hospitals in Seoul did not seem to exceed the benefits of using hospitals in Daegu. Further studies are required to investigate thoroughly about benefits, harms, and costs of using medical services in Seoul, which are indicative of possible overuses of medical services by patients from non-capital region.

The present study has several limitations. First, effect of cancer stages were not considered properly in the study but only with stratified analysis and subject restriction. Further studies focusing association between geographical areas and survival of cancer patients with more advanced stages are required. Second, causes of death could not be considered because it was impossible to integrate the raw data with the death data due to the Personal Information Protection Act. Third, conditions of patients who underwent chemotherapeutical treatments after resection of cancer were not properly reflected because types of chemotherapeutical agents and the frequency or amount of applications were not considered. Fourth, the number of observed events (death) was not sufficient and many censorings were made due to restricted period of the study. Despite these limitations, the major strengths of this study is that it provided a scientific evidence for cancer patients in making a rational choice for medical utilization in this era of centralization to the metropolis. Further analyses about quality and outcome of medical services according to hospital locations are required.

\section{CONFLICT OF INTEREST}

The authors have no conflicts of interest associated with the material presented in this paper.

\section{ORCID}

Nam-Soo Hong https://orcid.org/0000-0002-6598-9126

Kyeong Soo Lee https://orcid.org/0000-0001-8183-9462

Sin Kam https://orcid.org/0000-0002-5424-3820

Dong Hee Ryu https://orcid.org/0000-0002-2860-8849

\section{REFERENCES}

1. Kim JH, Lee JH, Lee JH. Changes in healthcare utilizations of cancer patients since the launch of KTX. J Korean Soc Railw 2010;13(2):236-243 (Korean).

2. Hong SO, Suh WS. Factors associated with utilization patterns of provincial patients discharged from general hospitals located in Seoul area. Korean J Health Educ Promot 2009;26(4): 117-127 (Korean).

3. Lee SJ, Park JY. Changing trends in Daegu and Gyeongbukbased patients' use of health facilities in Seoul. Health Policy Manag 2010;20(4):19-44 (Korean).

4. Nam MH, Kim SS, Park IS, Kang SH, Kim WJ, Choi SH, et al. A study on utilization of non-residential areal in operation patient. J Korea Acad Ind Coop Soc 2010;11(6):2078-2087 (Korean).

5. Park YH. Utilization patterns of other region inpatients in general hospitals located in Seoul area. Korean J Health Serv Manag 2011;5(3):63-76 (Korean).

6. Kim J, Lee J, Yoo W, Park S. Health impact assessment of high speed train (KTX) in Korea. Seoul: Korea Institute for Health and Social Affairs; 2008, p. 33-194 (Korean).

7. Schwartz LM, Woloshin S, Birkmeyer JD. How do elderly patients decide where to go for major surgery? Telephone interview survey. BMJ 2005;331(7520):821.

8. Do SR, Lee YH, Shin CW. Changes of patient's disease and characteristics of medical care use. Seoul: Korea Institute for Health and Social Affairs; 2004, p.10-166 (Korean).

9. Chang DM. A study on utilization behavior of cancer patients. Korean J Public Health 1998;24(2):106-117 (Korean).

10. Japanese Gastric Cancer Association. Japanese gastric cancer treatment guidelines 2010 (ver. 3). Gastric Cancer 2011;14(2): 113-123.

11. Lee JH, Kim JG, Jung HK, Kim JH, Jeong WK, Jeon TJ, et al. Synopsis on clinical practice guideline of gastric cancer in Korea: an evidence-based approach. Korean J Gastroenterol 2014;63 (2):66-81 (Korean).

12. Korean Academy of Medical Science. Korean clinical practice guideline for colon and rectal cancer v. 1.0; 2012 [cited 2017 Aug 5]. Available from: http://www.kaim.or.kr/files/guide/\%E C\%86\%8C\%ED\%99\%94\%EA\%B8\%B0_01.pdf(Korean).

13. Hall WH, Jani AB, Ryu JK, Narayan S, Vijayakumar S. The impact of age and comorbidity on survival outcomes and treatment patterns in prostate cancer. Prostate Cancer Prostatic Dis 2005; 8(1):22-30. 
14. van Eeghen EE, Bakker SD, van Bochove A, Loffeld RJ. Impact of age and comorbidity on survival in colorectal cancer. J Gastrointest Oncol 2015;6(6):605-612.

15. Quan H, Sundararajan V, Halfon P, Fong A, Burnand B, Luthi JC, et al. Coding algorithms for defining comorbidities in ICD-9CM and ICD-10 administrative data. Med Care 2005;43(11): 1130-1139.

16. Klabunde CN, Harlan LC, Warren JL. Data sources for measuring comorbidity: a comparison of hospital records and medicare claims for cancer patients. Med Care 2006;44(10):921928.

17. Finlayson EV, Birkmeyer JD. Effects of hospital volume on life expectancy after selected cancer operations in older adults: a decision analysis. J Am Coll Surg 2003;196(3):410-417.

18. Raval MV, Bilimoria KY, Talamonti MS. Quality improvement for pancreatic cancer care: is regionalization a feasible and effective mechanism? Surg Oncol Clin N Am 2010;19(2):371-390.

19. Begg CB, Cramer LD, Hoskins WJ, Brennan MF. Impact of hospital volume on operative mortality for major cancer surgery. JAMA 1998;280(20):1747-1751.

20. Schrag D, Earle C, Xu F, Panageas KS, Yabroff KR, Bristow RE, et al. Associations between hospital and surgeon procedure volumes and patient outcomes after ovarian cancer resection. J Natl Cancer Inst 2006;98(3):163-171.

21. Yun YH, Kim YA, Min YH, Park S, Won YJ, Kim DY, et al. The influence of hospital volume and surgical treatment delay on long-term survival after cancer surgery. Ann Oncol 2012;23 (10):2731-2737.

22. National Cancer Center. Annual report of cancer statistics in Korea in 2015. Goyang: National Cancer Center; 2015, p. 19194 (Korean).

23. Dudley RA, Johansen KL, Brand R, Rennie DJ, Milstein A. Selective referral to high-volume hospitals: estimating potentially avoidable deaths. JAMA 2000;283(9):1159-1166.

24. Hollenbeck BK, Dunn RL, Miller DC, Daignault S, Taub DA, Wei JT. Volume-based referral for cancer surgery: informing the debate. J Clin Oncol 2007;25(1):91-96.

25. Han DS. A revisit to policy agenda concerned with the distortion of functional differentiation among health care providers. Health Policy Manag 2010;20(4):1-18 (Korean).

26. Carr D, Goudas L, Lawrence D, Pirl W, Lau J, DeVine D, et al. Management of cancer symptoms: pain, depression, and fatigue. Evid Rep Technol Assess (Summ) 2002;61:368-374.

27. Earle CC, Neville BA. Under use of necessary care among cancer survivors. Cancer 2004;101(8):1712-1719.

28. Kim NS, Park EJ, Jeong JA, Hwang DK, Lee SH, Lee HY, et al. Analysis and improvement plan for rationalization of medical uses. Sejong: Korea Institute for Health and Social Affairs; 2015, p. 724 (Korean).

29. Lipitz-Snyderman A, Bach PB. Overuse of health care services: when less is more ... more or less. JAMA Intern Med 2013;173 (14):1277-1278. 
Supplemental Table 1. Electronic data interchange (EDI) codes for surgery

\begin{tabular}{|c|c|c|}
\hline Type of cancer & Type of surgery & EDI codes \\
\hline \multirow[t]{4}{*}{ Gastric cancer } & Total gastrectomy & $\begin{array}{l}\text { OA536, } 02533 \text { / } 02536 \text { (abdominal approach with / without LND), } 02534 \text { / } 02537 \text { (thoracic and abdominal approach } \\
\text { with / without LND) }\end{array}$ \\
\hline & Subtotal gastrectomy & $\begin{array}{l}\text { 00259, 02594 / } 00251 \text { (partial subtotal gastrectomy with / without LND), } 00252 \text { / } 00253 \text { (distal subtotal } \\
\text { gastrectomy with / without LND), } 00254 \text { / } 00255 \text { (pylorus-preserving subtotal gastrectomy with/ without LND) }\end{array}$ \\
\hline & Wedge resection & 00256 / 00257 (with / without LND) \\
\hline & Proximal resection & 00258 / 02598 (with / without LND) \\
\hline \multirow{3}{*}{ Colorectal cancer } & Total colectomy & QA672 / 02672 (with / without LND) \\
\hline & Segmental resection & $\begin{array}{l}\text { QA673 / } 02673 \text { (with / without LND), QA679 / } 02679 \text { (colectomy with proximal colostomy and stump with / without } \\
\text { LND), } 02891 \text { / } 02890 \text { / } 02892 \text { (resection of rectal tumor with transanal/transsacral or parasacral / abdominal } \\
\text { approach) }\end{array}$ \\
\hline & Rectal and sigmoid resection & $\begin{array}{l}\text { QA921 / } 02921 \text { (anterior resection with / without LND), } 02927 \text { (low anterior resection with ileoanal (J-pouch) } \\
\text { anastomosis), OA922 / 02922 (low anterior resection with/ without LND), 0A923 / } 02923 \text { (low anterior resec- } \\
\text { tion: abdominoperineal or abdominosacral approach with/without LND), QA92 / } 02924 \text { (abdominal pull through } \\
\text { operation with / without LND) }\end{array}$ \\
\hline
\end{tabular}

LND, lymph node dissection. 


\section{Journal of}

Supplemental Table 2. Comorbidity scores for the estimation of the Charlson comorbidity index

\begin{tabular}{|c|c|c|}
\hline Score & Comorbidity & ICD-10 code \\
\hline \multirow[t]{10}{*}{1} & Myocardial infarction & I21.X, |22.X, 125.2 \\
\hline & Congestive heart failure & I09.9, I11.0, I13.0, I13.2, I25.5, I42.0, I42.5- I42.9, I43.x, I50.x, P29.0 \\
\hline & Peripheral vascular disease & I70.x, I71.x, I73.1, I73.8, I73.9, I77.1, 179.0, I79.2, K55.1, K55.8, K55.9, Z95.8, Z95.9 \\
\hline & Cerebrovascular disease & G45.x, G46.x, H34.0, I60.x-169.x \\
\hline & Dementia & F00.x-F03.x, F05.1, G30.x, G31.1 \\
\hline & Chronic pulmonary disease & I27.8, I27.9, J40.x-J47.x, J60.x-J67.x, J68.4, J70.1, J70.3 \\
\hline & Rheumatic disease & M05.x, M06.x, M31.5, M32.x-M34.x, M35.1, M35.3, M36.0 \\
\hline & Peptic ulcer disease & $K 25 . x-K 28 . x$ \\
\hline & Mild liver disease & B18.x, K70.0-K70.3, K70.9, K71.3-K71.5, K71.7, K73.x, K74.x, K76.0, K76.2-K76.4, K76.8, K76.9, Z94.4 \\
\hline & Diabetes without chronic complication & $\begin{array}{l}\text { E10.0, E10.1, E10.6, E10.8, E10.9, E11.0, E11.1, E11.6, E11.8, E11.9, E12.0, E12.1, E12.6, E12.8, E12.9, } \\
\text { E13.0, E13.1, E13.6, E13.8, E13.9, E14.0, E14.1, E14.6, E14.8, E14.9 }\end{array}$ \\
\hline \multirow[t]{4}{*}{2} & Diabetes with chronic complication & E10.2-E10.5, E10.7, E11.2-E11.5, E11.7, E12.2-E12.5, E12.7, E13.2-E13.5, E13.7, E14.2-E14.5, E14.7 \\
\hline & Hemiplegia or paraplegia & G04.1, G11.4, G80.1, G80.2, G81.x, G82.x, G83.0 - G83.4, G83.9 \\
\hline & Renal disease & I12.0, I13.1, N03.2 - N03.7, N05.2 - N05.7, N18.x, N19.x, N25.0, Z49.0-Z49.2, Z94.0, Z99.2 \\
\hline & $\begin{array}{l}\text { Any malignancy, including lymphoma and leukemia, } \\
\text { excluding malignant neoplasm of skin }\end{array}$ & $\begin{array}{l}\text { C00.x-C26.x, C30.x-C34.x, C37.x-C41.x, C43.x, C45.x-C58.x, C60.x-C76.x, C81.x-C85.x, C88.x, } \\
\text { C90.x-C97.x }\end{array}$ \\
\hline 3 & Moderate or severe liver disease & I85.0, I85.9, I86.4, I98.2, K70.4, K71.1, K72.1, K72.9, K76.5, K76.6, K76.7 \\
\hline \multirow[t]{2}{*}{6} & Metastatic solid tumor & C77.x-C80.x \\
\hline & AIDS/HIV & B20.x-B22.x, B24.x \\
\hline
\end{tabular}

AIDS/HIV, acquired immune deficiency syndrome and human immunodeficiency virus infection; ICD-10, International Statistical Classification of Diseases, 10th revision. 